\title{
Differences in plasma metabolomics between sows fed DL-methionine and its hydroxy analogue reveal a strong association of milk composition and neonatal growth with maternal methionine nutrition
}

\author{
Xiaoling Zhang ${ }^{1} \dagger$, Hao $\operatorname{Li}^{1} \dagger$, Guangmang $\operatorname{Liu}^{1} \dagger$, Haifeng Wan ${ }^{1} \dagger$, Yves Mercier ${ }^{2}$, Caimei Wu ${ }^{1}$, \\ Xiuqun $\mathrm{Wu}^{1}$, Lianqiang $\mathrm{Che}^{1}$, Yan $\mathrm{Lin}^{1}{ }^{1}$, Shengyu $\mathrm{Xu}^{1}$, Gang Tian ${ }^{1}$, Daiwen Chen ${ }^{1}$, De Wu ${ }^{1}$ \\ and Zhengfeng Fang ${ }^{1 *}$ \\ ${ }^{1}$ Key Laboratory for Animal Disease-Resistance Nutrition of China Ministry of Education, Animal Nutrition Institute, \\ Sichuan Agricultural University, Ya'an 625014, People's Republic of China \\ ${ }^{2}$ Adisseo France SAS, CERN, Commentry, France
}

(Submitted 11 November 2013 - Final revision received 6 October 2014 - Accepted 7 November 2014 - First published online 2 February 2015)

\section{Abstract}

The aim of the present study was to determine whether increased consumption of methionine as DL-methionine (DLM) or its hydroxy analogue DL-2-hydroxy-4-methylthiobutanoic acid (HMTBA) could benefit milk synthesis and neonatal growth. For this purpose, eighteen cross-bred (Landrace $\times$ Yorkshire) primiparous sows were fed a control (CON), DLM or HMTBA diet ( $n 6$ per diet) from 0 to $14 \mathrm{~d}$ post-partum. At postnatal day 14, piglets in the HMTBA group had higher body weight $(P=0.02)$ than those in the CON group, tended $(P=0.07)$ to be higher than those in the DLM group, and had higher $(P<0.05)$ mRNA abundance of jejunal fatty acid-binding protein 2 , intestinal than those in the CON and DLM groups. Compared with the CON diet-fed sows, milk protein, non-fat solid, and lysine, histidine and ornithine concentrations decreased in the DLM diet-fed sows $(P<0.05)$, and milk fat, lactose, and cysteine and taurine concentrations increased in the HMTBA diet-fed sows $(P<0.05)$. Plasma homocysteine and urea $\mathrm{N}$ concentrations that averaged across time were increased $(P<0.05)$ in sows fed the DLM diet compared with those fed the CON diet. Metabolomic results based on ${ }^{1} \mathrm{H}$ NMR spectroscopy revealed that consumption of the HMTBA and DLM diets increased $(P<0.05)$ both sow plasma methionine and valine levels; however, consumption of the DLM diet led to lower $(P<0.05)$ plasma levels of lysine, tyrosine, glucose and acetate and higher $(P<0.05)$ plasma levels of citrate, lactate, formate, glycerol, myo-inositol and $N$-acetyl glycoprotein in sows. Collectively, neonatal growth and milk synthesis were regulated by dietary methionine levels and sources, which resulted in marked alterations in amino acid, lipid and glycogen metabolism.

Key words: Methionine hydroxy analogue: Plasma metabolomics: Milk synthesis: Sows: Piglets

The sulphur amino acids (SAA), methionine, homocysteine and cysteine play an important role in human and animal nutrition and health ${ }^{(1,2)}$. Recent studies have shown that adequate amounts of SAA are necessary for intestinal health and normal growth of neonates ${ }^{(3,4)}$. However, previous research that analysed the amino acids (AA) profile in sow milk has suggested that supply of methionine in the diet may not match the requirements of growing neonates. Interestingly, concentrations of a majority of AA including lysine, leucine, arginine and valine in sow milk increase as the lactation period advances from 5 to $19 \mathrm{~d}$ post-partum ${ }^{(5)}$. In contrast, no significant variations between lactation periods were observed in relation to the concentrations of several AA, especially methionine and threonine, in sow milk ${ }^{(5)}$. Studies in piglets using isotope tracers have indicated that roughly one-third of dietary intake of essential AA including lysine, leucine and phenylalanine is consumed in first-pass metabolism by the intestine, and that AA catabolism by intestinal mucosal cells is quantitatively greater than AA incorporation into mucosal protein ${ }^{(6)}$. Further in vitro studies have indicated that $50-70 \%$ of leucine, $25 \%$ of methionine, threonine and proline, and $15 \%$ of lysine and arginine are utilised for bacterial protein synthesis ${ }^{(7)}$. Given that nutrients are first consumed by the intestine, the extensive metabolism of

\footnotetext{
Abbreviations: AA, amino acids; ADMA, asymmetric dimethylarginine; CON, control; DDAH, dimethylarginine dimethylaminohydrolase; DLM, DLmethionine; DMA, dimethylamine; FABP2, fatty acid-binding protein 2; HMTBA, DL-2-hydroxy-4-methylthiobutanoic acid; OPLS-DA, orthogonal projection to latent structure discriminant analysis; SAA, sulphur amino acids.
}

* Corresponding author: Professor Z. Fang, fax +86 28 86290920, email fangzhengfeng@hotmail.com

† These authors contributed equally to the work. 
dietary essential AA by the intestine ${ }^{(6)}$ or commensal intestinal bacteria $^{(7)}$ may result in a decrease in their availability for protein synthesis in other tissues such as the mammary glands. In support of this notion, milk protein synthesis in dairy cows has been shown to increase more by jugular infusion of AA than by post-ruminal infusion of AA, indicating a significant decrease in dietary AA metabolism by the intestine and thus an increase in AA availability for delivery to the mammary glands ${ }^{(8)}$.

Based on plasma urea $\mathrm{N}$, lysine and threonine have been identified to be the first- and second-limiting AA, respectively, in maize-soyabean diets of lactating sows ${ }^{(9)}$. However, studies on sows implanted with catheters in a carotid artery and the main mammary vein have indicated that AA needed for milk synthesis is defined by the maximal uptake of plasma AA by porcine mammary glands ${ }^{(10)}$. It has been observed in piglets that the extensive metabolism of dietary AA by the intestine makes the net portal balance of methionine (48\% intake) and threonine (38\% intake) greatly lower than that of lysine ( $65 \%$ intake); therefore, it has been proposed that methionine and threonine rather than lysine are the limiting AA for extra-intestinal protein synthesis ${ }^{(6)}$. In support of this view, milk synthesis in lactating sows and high-producing dairy cows has been shown to increase by an increased inclusion of dietary threonine ${ }^{(11)}$ and jugular-infused methionine ${ }^{(12)}$, respectively. Further studies on mammary epithelial cells and tissues have indicated that both methionine and threonine are the limiting substrates for protein synthesis in the mammary glands; however, methionine is also a potential regulator of milk protein synthesis $^{(13)}$. Taken together, these studies have indicated the considerable importance of adequate methionine availability for the mammary glands to sustain milk production.

However, because homocysteine, the intermediate compound of methionine in the trans-methylation cycle, is toxic to humans and animals, methionine is considered to be the most toxic $\mathrm{AA}^{(14)}$. This may have discouraged the attempts to increase methionine availability for extra-intestinal tissues by increasing methionine consumption. Remarkably, previous studies in ducks ${ }^{(15)}$ have found that consumption of the methionine hydroxy analogue, DL-2-hydroxy-4-methylthiobutanoic acid (HMTBA), resulted in less plasma homocysteine consumption compared with equimolar DL-methionine (DLM) consumption. Moreover, our recent studies conducted in piglets have indicated that HMTBA may be less extensively lost compared with DLM when they are absorbed from the lumen into the portal blood ${ }^{(1,16-18)}$. It appears that the potential less toxicity and higher extra-intestinal availability of HMTBA relative to DLM may provide a promising implication for HMTBA utilisation in lactating animals. Studies in pigs may be beneficial for our understanding in human lactation, as pigs and humans have similar anatomic and physiological characteristics including the cardiovascular, urinary, integumentary and digestive systems ${ }^{(19)}$. The aim of the present study was to determine how neonatal pigs respond to increased consumption of methionine as DLM or HMTBA by lactating sows, and we hypothesised that supplemental dietary methionine sources could result in the changes in sow plasma metabolite concentrations and thus affect milk synthesis and neonatal pig growth.

\section{Materials and methods}

\section{Animals and diets}

The protocol of the present study was approved by the Animal Care and Use Committee of Animal Nutrition Institute, Sichuan Agricultural University, and carried out in accordance with the National Research Council's Guide for the Care and Use of Laboratory Animals. In the present experiment, eighteen pregnant cross-bred (Landrace $\times$ Yorkshire) primiparous sows artificially inseminated with mixed semen from two Duroc boars were used. On day 110 of gestation, sows were moved into farrowing crates $(2.1 \mathrm{~m} \times 0.7 \mathrm{~m})$ with an area $(2.1 \mathrm{~m} \times 0.6 \mathrm{~m})$ for newborn pigs on each side of the crate in an environmentally regulated farrowing house. Temperature in the farrowing house was maintained at $20 \pm 1^{\circ} \mathrm{C}$, and heat lamps provided supplemental heat to the piglets. All sows were fed the control (CON) diet until farrowing. During farrowing, six sows continued to receive the CON diet, and the other sows were fed the DLM or HMTBA diet, with six sows per diet. The CON diet was formulated based on the nutrition requirement of lactating sows as recommended by the National Research Council (1998) ${ }^{(20)}$ (Table 1). According to the National Research Council (1998), in the ideal AA profile for lactating sows, dietary ratios of methionine and methionine + cystine to lysine were 26:100 and 48:100, respectively. In contrast, Dourmad et al. $^{(21)}$ recommended dietary ratios of methionine and methionine + cystine to lysine to be 30:100 and 60:100, respectively, which means that compared with the recommendation of the National Research Council (1998), dietary ratios of methionine and methionine + cystine to lysine have been found to be increased by 15 and $25 \%$, respectively. In the present study, the CON diet was formulated to contain methionine and lysine at 0.25 and $0.97 \%$, respectively, and the dietary ratio of methionine:lysine (26:100) was the same as that recommended by the National Research Council (1998). Accordingly, the percentage of dietary methionine + cystine in the CON diet was up to $0.53 \%$, at $25 \%$ of which, namely, $1.34 \mathrm{~kg}$ DLM (99\%) and $1.51 \mathrm{~kg}$ HMTBA (88\%) were added to $1000 \cdot 05 \mathrm{~kg}$ of the CON diet at the expense of maize to form the DLM and HMTBA diets, respectively. The time span of farrowing between the sows was within $3 \mathrm{~d}$. At day 0 post-partum, the backfat thickness of sows was 11.06 (SD $2 \cdot 04$ ), $11 \cdot 17$ (SD 2.87) and 12.83 (SD 1.96) $\mathrm{mm}$ for the CON, DLM and HMTBA treatments, respectively, and the body weight of sows was 155.68 (SD 17.82), 145.27 (SD 22.85) and 154.80 (SD 13.78) kg for the CON, DLM and HMTBA treatments, respectively. Within $12 \mathrm{~h}$ of farrowing, all litters were standardised based on the number and body weight of piglets so that there were ten piglets per sow, and the average body weight ( $\mathrm{CV}<3.0 \%$ ) of piglets was 1.42 (SD 0.02), 1.42 (SD 0.03) and 1.44 (SD 0.04) kg for the CON, DLM and HMTBA treatments, respectively. Sows had free access to diets and water throughout the experimental period. 
Table 1. Ingredients and composition of the control (CON) diet of sows ${ }^{*}$

\begin{tabular}{lclr}
\hline Ingredients & Content $(\mathrm{kg})$ & Composition $\dagger$ & $\%$ \\
\hline Maize & 582 & CP & $16 \cdot 10$ \\
Wheat bran & 60 & Lys & 0.97 \\
Soyabean meal (CP 43\%) & 240 & Met & 0.25 \\
Fructose-glucose syrup & 20 & Met + cystine & 0.53 \\
Glucose & 25 & Thr & 0.63 \\
Soyabean oil & 35 & Trp & 0.19 \\
Lys-HCl & 1.45 & Val & 0.83 \\
Thr & 0.08 & Digestible Lys & 0.85 \\
Val (99\%) & 0.92 & Digestible Met & 0.23 \\
Dicalcium phosphate & 14.1 & Digestible & 0.46 \\
& & Met + cystine & \\
Limestone & 10.5 & Ca & 0.80 \\
NaCl & 4 & Total P & 0.64 \\
Premix $\ddagger$ & 5 & Available P & 0.38 \\
Choline chloride (50\%) & 2 & & \\
Total & 1000.05 & & \\
& & & \\
\hline
\end{tabular}

$\mathrm{CP}$, crude protein

* The DL-methionine (DLM) and DL-2-hydroxy-4-methylthiobutanoic acid (HMTBA) diets were prepared by adding $1.34 \mathrm{~kg}$ DLM $(99 \%)$ and $1.51 \mathrm{~kg}$ HMTBA $(88 \%)$, respectively, to $1000.05 \mathrm{~kg}$ of the CON diet at the expense of maize. Each diet (per $\mathrm{kg}$ ) contained $14200 \mathrm{~kJ}$ digestible energy.

†The compositional values were calculated from the tabulated values of the National Research Council $(1998)^{(20)}$.

† Provided per $\mathrm{kg}$ of diet: retinol, $3600 \mathrm{mg}$; vitamin $\mathrm{D}_{3}, 70 \mathrm{mg}$; vitamin $\mathrm{E}, 100 \mathrm{mg}$ menadione, $3.5 \mathrm{mg}$; thiamin, $3.5 \mathrm{mg}$; riboflavin, $8.5 \mathrm{mg}$; niacin, $35 \mathrm{mg}$; D-pantothenic acid, $21 \mathrm{mg}$; vitamin $B_{6}, 3.5 \mathrm{mg}$; vitamin $B_{12}, 35 \mathrm{mg}$; D-biotin, $420 \mathrm{mg}$; folic acid, $2.5 \mathrm{mg}$.

§Provided per kg of diet: Cu, $10 \mathrm{mg} ; \mathrm{Fe}, 120 \mathrm{mg} ; \mathrm{Mn}, 30 \mathrm{mg} ; \mathrm{Zn}, 80 \mathrm{mg}$; I, $0.21 \mathrm{mg}$; $\mathrm{Se}, 0.23 \mathrm{mg}$; antioxidant, $100 \mathrm{mg}$; anti-mould additive, $500 \mathrm{mg}$

\section{Collection of blood, milk and tissue samples}

At 30 min before the initiation of the morning meal, following an overnight period of feed withdrawal, blood samples $(10 \mathrm{ml})$ from each sow at days 7 and 14 post-partum were collected from the superior vena cava into heparinised tubes and immediately centrifuged for $10 \mathrm{~min}$ at $4000 \mathrm{rpm}$ and $4^{\circ} \mathrm{C}$. Supernatants were divided into four subsamples and stored at $-80^{\circ} \mathrm{C}$ until analysis. Milk samples $(20 \mathrm{ml})$ from each sow were also collected at day 14 post-partum before the morning meal as described previously ${ }^{(5)}$. Briefly, piglets were separated from their dams for $90 \mathrm{~min}$ initially, and then $10 \mathrm{IU}$ (20 mg) of oxytocin (a nonapeptide; $1 \mathrm{IU}$ of oxytocin is equivalent to about $2 \mathrm{mg}$ of pure peptide) were injected into the ear vein of each sow, and the functional pectoral and inguinal glands were milked manually to collect milk samples, which were stored at $-20^{\circ} \mathrm{C}$ until analysis. At postnatal day 14 , one piglet with an average body weight of the litter was selected from each litter for collecting intestinal samples as described previously ${ }^{(14)}$. Briefly, the intestine was rapidly excised from the ligament of Treitz to the ileo-caecal valve, freed of its mesenteric fat and rinsed in ice-cold saline. Measuring from the ligament of Treitz, a $2 \mathrm{~cm}$ section of tissue was removed, snap-frozen in liquid $\mathrm{N}_{2}$ and stored at $-80^{\circ} \mathrm{C}$ for subsequent RNA isolation.

\section{Measurement of sow and piglet performance}

Body weight and backfat thickness of each sow were determined before the morning meal at days 0 and 14 post-partum. Backfat thickness was measured at $65 \mathrm{~mm}$ left side of the dorsal midline at the last rib level using ultrasound (Renco Lean-Meater). Feed intake of each sow was recorded daily. Body weight of piglets was determined before the morning meal at postnatal days 0, 7 and 14 .

\section{Analysis of milk composition}

For milk composition analysis, frozen milk samples were thawed at $4^{\circ} \mathrm{C}$, and then $10 \mathrm{ml}$ of each sample were used for the analysis of milk fat, lactose, protein and non-fat solid contents using an ultrasonic milk analyser (MILKYWAY-CP2; Hangzhou Simple Technology Company, Limited). Milk fat, lactose, protein and non-fat solid contents were automatically calculated based on the changes in ultrasonic propagation parameters such as velocity and amplitude of ultrasonic pulse emitted and received after travelling through the milk ${ }^{(22)}$.

\section{Analysis of plasma urea nitrogen and milk amino acids}

Frozen plasma and milk samples were thawed at $4^{\circ} \mathrm{C}$, and $1 \mathrm{ml}$ of each sample and $2.5 \mathrm{ml}$ of $7.5 \%(\mathrm{w} / \mathrm{v})$ TCA solution were mixed thoroughly and centrifuged at $12000 \mathrm{~g}$ and $4{ }^{\circ} \mathrm{C}$ for $15 \mathrm{~min}$. Then, the supernatant fluid was collected, and AA and urea $\mathrm{N}$ concentrations were determined by ion-exchange chromatography using an L8800 high-speed AA analyser (Hitachi), as described previously ${ }^{(16)}$.

\section{Analysis of plasma homocysteine concentration}

Plasma homocysteine concentration was determined using a homocysteine detection kit (Jiancheng Bioengineering Limited), according to the manufacturer's instructions, and the assay principle was based on the method of enzymatic cycling, as described previously ${ }^{(23)}$. Briefly, oxidised homocysteine was first reduced to free homocysteine, which then reacts with a co-substrate, $S$-adenosyl-L-methionine, catalysed by homocysteine $S$-methyltransferase. The co-substrate conversion product was amplified by coupled enzymatic cycling reactions. The homocysteine level in the sample was indirectly proportional to the rate of the absorbance of NADH conversion to $\mathrm{NAD}^{+}$and was measured at $340 \mathrm{~nm}$.

\section{RNA extraction and real-time $P C R$}

Jejunal tissue samples were used to detect the expression of genes related to the intestinal transport of dietary nutrients. The detected genes included apoA-IV (APOA4) and fatty acid-binding protein 2 (FABP2), intestinal. Total RNA was extracted from the frozen samples using the RNAiso Plus reagent (TaKaRa Corporation), according to the manufacturer's specifications. Concentration of RNA in the samples was quantified using a DU-800 nucleic and protein detector (Beckman Coulter, Inc.) at an optical density (OD) of $260 \mathrm{~nm}$, and the ratio of $\mathrm{OD}_{260}: \mathrm{OD}_{280}$ between 1.8 and $2 \cdot 0$ was acceptable. Integrity of RNA was verified by electrophoresis on a $1 \%$ agarose gel stained with ethidium bromide. Real-time PCR was performed using the SYBR Green method 
and the ABI 7900HT Sequence Detection System (Applied Biosystems). Briefly, first-strand complementary DNA were synthesised from $1 \mu \mathrm{g}$ of total RNA as described previously ${ }^{(16)}$. The thermal cycling parameters were as follows: $95^{\circ} \mathrm{C}$ for $30 \mathrm{~s}$, followed by forty cycles at $95^{\circ} \mathrm{C}$ for $15 \mathrm{~s}$ and $60^{\circ} \mathrm{C}$ for $34 \mathrm{~s}$, and finally followed by the dissociation step at $95^{\circ} \mathrm{C}$ for $15 \mathrm{~s}, 60^{\circ} \mathrm{C}$ for $1 \mathrm{~min}$ and $95^{\circ} \mathrm{C}$ for $15 \mathrm{~s}$. To confirm the specific amplification, melt curve analysis was performed, and PCR products were also detected on ethidium bromide-stained $2 \%$ agarose gel after electrophoresis using Tris-acetate-EDTA buffer. The nucleotide primer sequences of $18 S$ RNA (forward, 5'-GACTCAACACGGGAAACCTCAC-3'; reverse, 5'-ATCGCTCCACCAACTAAGAACG-3'), APOA4 (forward, 5'-GTGGCTACTGTGATGTGGGACTAC- $3^{\prime}$; reverse, 5'-CCAAGTTTGTCCTGGAAGAGAGTG- $3^{\prime}$ ) and FABP2 (forward, 5'-TACAGCCTCGCAGACGGAAC- $3^{\prime}$; reverse, $5^{\prime}$-CCTCTTGGCTTCTACTCCTTCATAC- $3^{\prime}$ ) used for the real-time PCR were designed based on the mRNA sequences in pigs (accession no. NR_046261.1, NM_214388.1 and NM_001031780.1 for the 18S RNA, APOA4 and FABP2, respectively), and synthesised by Chengdu Tiantai Biological Company. These primers were designed to flank known or putative introns, thus preventing the amplification of any contaminating genomic DNA. The relative mRNA abundances of the detected genes in the jejunum samples were calculated using the $2^{-\Delta \Delta C_{\mathrm{t}}} \operatorname{method}^{(24)}$, and all data were normalised with $18 S$ RNA in the same samples.

\section{NMR spectroscopy}

Plasma samples were prepared by mixing $200 \mu \mathrm{l}$ of plasma with $400 \mu \mathrm{l}$ of saline containing $50 \%{ }^{2} \mathrm{H}_{2} \mathrm{O}$ (for field-frequency lock purposes). The proton NMR spectra of plasma were recorded at $298 \mathrm{~K}$ using a Bruker Avance DRX-600 spectrometer (Bruker BioSpin) operating at a ${ }^{1} \mathrm{H}$ frequency of $600 \cdot 11 \mathrm{MHz}$ with a triple-resonance, high-resolution probe. A water-presaturated Carr-Purcell-Meiboom-Gill pulse sequence (recycle delay $-90^{\circ}-\left(\tau-180^{\circ}-\tau\right) n-$ acquisition) was used to attenuate NMR signals from macromolecules. The spin-spin relaxation delay $(2 n \tau)$ of $200 \mathrm{~ms}$ was employed. Typically, a $90^{\circ}$ pulse was set to $10 \cdot 0 \mu \mathrm{s}$, and thirty-two transients were collected into $32 \mathrm{k}$ data points for each spectrum with a spectral width of 20 parts per million. For assignment purposes, five two-dimensional NMR spectra were acquired for the selected samples: ${ }^{1} \mathrm{H}-{ }^{1} \mathrm{H}$ J-resolved spectroscopy; ${ }^{1} \mathrm{H}-{ }^{1} \mathrm{H}$ correlation spectroscopy; ${ }^{1} \mathrm{H}-{ }^{1} \mathrm{H}$ total correlation spectroscopy; ${ }^{1} \mathrm{H}-{ }^{13} \mathrm{C}$ heteronuclear singlequantum coherence spectroscopy; ${ }^{1} \mathrm{H}-{ }^{13} \mathrm{C}$ heteronuclear multiple-bond correlation spectroscopy.

\section{NMR spectral processes}

Free induction decays were multiplied by an exponential window function with a $1 \mathrm{~Hz}$ line-broadening factor before Fourier transformation. All NMR spectra were initially phase-adjusted, and then the baseline was corrected using Mestrenova 7.0 software (Mestrelab Research SL). Chemical shift was referenced to the peak of the methyl proton of L-lactate at $\delta 1.33$.

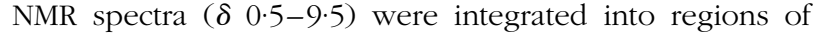
0.002 parts per million wide using Mestrenova 7.0 software (Mestrelab Research SL). Regions distorted by imperfect water saturation were discarded as well as the regions containing urea signals. These regions are $\delta 4 \cdot 47-5 \cdot 18, \delta 5 \cdot 5-6 \cdot 0$ and $\delta$ $4 \cdot 28-4 \cdot 45$. Subsequently, each integral region was normalised to the total sum of all the integral regions for each spectrum before pattern recognition analyses.

\section{Statistical analysis}

Data are presented as means and standard deviations. For comparisons of backfat thickness, body weight and concentrations of plasma homocysteine and urea $\mathrm{N}$ among the dietary treatment groups, a repeated-measures ANOVA (version 8.1, SAS Institute, Inc.) was performed with time as the repeated-measure effect. Differences in the means of milk composition and mRNA abundance were analysed by one-way ANOVA followed by Fisher's least significant difference test. Multivariate data analysis was carried out on the normalised NMR datasets with the software package SIMCA-P+ (version 11.0; Umetrics). Principal component analysis was performed to show an overview of intrinsic similarity/dissimilarity within the dataset. The orthogonal projection to latent structure discriminant analysis (OPLS-DA) was further carried out using the unit-variance scaled NMR data as the X-matrix and class information as the Y-matrix ${ }^{(25)}$. The quality of the model was assessed by the parameters $R^{2} X$, representing the total explained variations for the X-matrix, and $Q^{2}$, indicating model predictability. The models were validated by two methods: a cross-validation method ${ }^{(26)}$ and a permutation test ${ }^{(27)}$. The models were interpreted by coefficient-coded loading plots. The loadings were back-transformed in Excel (Microsoft) and plotted with colour-coded absolute coefficient values $(|r|)$ of the variables in MATLAB (version 7.1; The Mathworks Inc.) ${ }^{(26)}$. The coefficient plot indicated the significance of variables (resonances) that contributed to the differentiation of classes of interest. The significant discriminatory metabolites were indicated by the red colour, whereas no significance was indicated by the blue colour. In the present study, appropriate correlation coefficients were used as the cut-off values (depending on the number of animals used) for statistical significance based on the significance of discrimination at the level of $P<0.05$; such significance was determined according to Pearson's product-moment correlation coefficient test ${ }^{(26)} . P \leq 0 \cdot 05$ was considered significant, and $P<0 \cdot 10$ was considered to have a tendency towards difference.

\section{Results}

\section{Porcine performance}

At day 14 post-partum, backfat thickness (11.72 (SD 2.05), 10.83 (SD 3.07) and 14.22 (SD 3.66) $\mathrm{mm}$ for the CON, DLM and HMTBA treatments, respectively) and body weight (155.47 (SD 12.80), 141.73 (SD 19.60) and 153.00 (SD 15.33) kg for the CON, DLM and HMTBA treatments, respectively) of sows did not differ $(P>0 \cdot 10)$ among the dietary treatment 
groups. The total feed consumption (69.08 (SD 10.00), 63.95 (SD 13.18) and 66.34 (SD 10.98) kg for the CON, DLM and HMTBA treatments, respectively) and daily digestible energy intake as a percentage of metabolic body weight (1590.96 (SD 196.82), 1572.71 (SD 229.45) and 1544.80 (SD 195.68) kJ for the CON, DLM and HMTBA treatments, respectively) were also not different $(P>0 \cdot 10)$ among the dietary treatment groups during the experimental phase. However, the body weight of suckling piglets at postnatal day 14 in the HMTBA group was higher $(P=0.02)$ than that in the CON group and tended $(P=0.07)$ to be higher than that in the DLM group (Table 2).

\section{Plasma homocysteine and urea nitrogen concentrations}

There was no effect of time $(P>0 \cdot 10)$ for plasma homocysteine and urea $\mathrm{N}$ concentrations. Plasma homocysteine (11.68 (SD 1.70) v. 9.49 (SD 1.58) $\mu \mathrm{mol} / \mathrm{l})$ and urea $\mathrm{N}$ (4836 (SD 852) v. $3898(\mathrm{SD} 453) \mu \mathrm{mol} / \mathrm{l})$ concentrations that averaged across time were higher $(P<0.05)$ in the DLM-fed sows than in the CON-fed sows. Plasma urea $\mathrm{N}$ concentration that averaged across time was also higher $(P<0.05)$ in the DLM-fed sows than in the HMTBA-fed sows (4171 (SD 622) $\mu \mathrm{mol} / \mathrm{l}$ ). However, neither plasma homocysteine (10.28 (SD 1.87) $\mu \mathrm{mol} / \mathrm{l})$ nor urea $\mathrm{N}$ concentration that averaged across time was different $(P>0 \cdot 10)$ between the HMTBA-fed and CON-fed sows.

\section{Milk amino acid concentrations}

Table 3 presents milk AA concentrations in sows fed the CON, DLM or HMTBA diet at day 14 post-partum. Milk lysine concentration in the DLM-fed sows was lower $(P<0.05)$ than that in the CON-fed sows and tended $(P<0 \cdot 10)$ to be lower than that in the HMTBA-fed sows. Milk histidine concentration was lower $(P<0.05)$ in the DLM-fed sows than in the CON-fed and HMTBA-fed sows. The DLM-fed sows also had lower $(P<0.05)$ ornithine concentration than the CON-fed sows. The HMTBA-fed sows had higher taurine $(P<0.05)$ concentration, but lower $(P<0.05)$ alanine concentration than the CON-fed sows. Milk cysteine concentration was higher $(P<0.05)$ in the HMTBA-fed sows than in the CON-fed and DLM-fed sows.

Table 2. Body weight $(\mathrm{kg})$ of piglets at postnatal days 0,7 and 14 (Mean values and standard deviations, $n 6$ )

\begin{tabular}{|c|c|c|c|c|c|c|}
\hline & \multicolumn{2}{|c|}{$\mathrm{CON}$} & \multicolumn{2}{|c|}{ DLM } & \multicolumn{2}{|c|}{ HMTBA } \\
\hline & Mean & SD & Mean & SD & Mean & SD \\
\hline Day 0 & $1.42^{d}$ & 0.02 & $1.42^{d}$ & 0.03 & $1.44^{\mathrm{d}}$ & 0.04 \\
\hline Day 7 & $2 \cdot 50^{\mathrm{c}}$ & 0.25 & $2 \cdot 49^{c}$ & 0.26 & $2 \cdot 58^{\mathrm{C}}$ & 0.19 \\
\hline Day 14 & $3.63^{b}$ & 0.53 & $3 \cdot 77^{\mathrm{a}, \mathrm{b} *}$ & 0.69 & $4 \cdot 14^{\mathrm{a}}$ & 0.39 \\
\hline
\end{tabular}

CON, control; DLM, DL-methionine; HMTBA, DL-2-hydroxy-4-methylthiobutanoic acid.

a,b,c,d Mean values with unlike superscript letters were significantly different $(P<0.05)$.

${ }^{\star}$ Mean value tended to be different from that of the HMTBA group $(P<0 \cdot 10)$.
Table 3. Effects of diets supplemented with DL-methionine (DLM) or DL-2-hydroxy-4-methylthiobutanoic acid (HMTBA) on milk amino acid concentrations $(\mu \mathrm{mol} / \mathrm{l})$ in sows at day 14 post-partum

(Mean values and standard deviations, $n 6$ )

\begin{tabular}{|c|c|c|c|c|c|c|}
\hline & \multicolumn{2}{|c|}{ CON } & \multicolumn{2}{|c|}{ DLM } & \multicolumn{2}{|c|}{ HMTBA } \\
\hline & Mean & SD & Mean & SD & Mean & SD \\
\hline Met & 13 & 3 & 14 & 6 & 19 & 8 \\
\hline Lys & $68^{\mathrm{a}}$ & 12 & $48^{b_{\star}}$ & 12 & $62^{a, b}$ & 13 \\
\hline Thr & 40 & 13 & 35 & 13 & 32 & 13 \\
\hline Leu & 24 & 15 & 22 & 4 & 21 & 7 \\
\hline Ile & 4 & 7 & 1 & 3 & 1 & 2 \\
\hline Phe & 16 & 8 & 22 & 9 & 18 & 7 \\
\hline Val & 28 & 11 & 24 & 7 & 31 & 14 \\
\hline His & $39^{a}$ & 12 & $18^{\mathrm{b}}$ & 13 & $42^{\mathrm{a}}$ & 15 \\
\hline Pro & 197 & 34 & 175 & 70 & 158 & 38 \\
\hline Arg & 56 & 18 & 57 & 22 & 45 & 11 \\
\hline Cys & $14^{\mathrm{b}}$ & 4 & $13^{\mathrm{b}}$ & 4 & $21^{a}$ & 3 \\
\hline Ala & $190^{\mathrm{a}}$ & 56 & $146^{\mathrm{a}, \mathrm{b}}$ & 58 & $112^{\mathrm{b}}$ & 47 \\
\hline Ser & 45 & 11 & 58 & 18 & 40 & 17 \\
\hline Gln and Glu & 334 & 131 & 368 & 109 & 307 & 80 \\
\hline Gly & 211 & 53 & 175 & 94 & 152 & 47 \\
\hline Tyr & 24 & 9 & 27 & 7 & 25 & 6 \\
\hline Orn & $20^{\mathrm{a}}$ & 8 & $10^{\mathrm{b}}$ & 5 & $16^{a, b}$ & 5 \\
\hline Tau & $1268^{\mathrm{b}}$ & 329 & $1416^{a, b}$ & 456 & $1759^{\mathrm{a}}$ & 303 \\
\hline
\end{tabular}

CON, control.

${ }^{a, b}$ Mean values with unlike superscript letters were significantly different $(P<0.05)$.

${ }^{\star}$ Mean value tended to be different from that of the HMTBA group $(P<0.10)$.

\section{Milk fat, lactose, protein and non-fat solid contents}

Milk fat and lactose contents were higher $(P<0.05)$ in the HMTBA-fed sows than in the CON-fed and DLM-fed sows, whereas milk protein and non-fat solid contents were lower $(P<0.05)$ in the DLM-fed sows than in the CON-fed and HMTBA-fed sows at $14 \mathrm{~d}$ post-partum (Fig. 1).

\section{mRNA abundance of genes related to intestinal nutrient transport}

Fig. 2 shows the mRNA abundance of genes related to nutrient transport in the jejunum of 14-d-old suckling piglets. The mRNA abundance of the APAO4 gene was not different $(P>0 \cdot 10)$ among the dietary treatment groups. However, the mRNA abundance of $F A B P 2$ was higher $(P<0.05)$ in piglets reared by the HMTBA-fed sows than in those reared by the CON-fed and DLM-fed sows.

\section{Multivariate data analysis of NMR datasets}

Principal component analysis was initially performed on the spectral data, and two principal components were calculated for the six dietary treatment groups, with 35.3 and $27 \cdot 1 \%$ of the total variation being explained by principal components 1 and 2, respectively. The principal component analysis (Fig. 3(A)) showed that separations were absent in the plasma metabolic profiles at 7 and $14 \mathrm{~d}$ post-partum from the respective groups. Therefore, the respective groups of sows at 7 and $14 \mathrm{~d}$ post-partum were merged to represent the CON, DLM and HMTBA groups, respectively (i.e. CONday $7+$ CON-day $14=\mathrm{CON} ; \quad$ DLM-day $7+$ DLM-day $14=$ DLM; HMTBA-day $7+$ HMTBA-day $14=$ HMTBA $)$. 


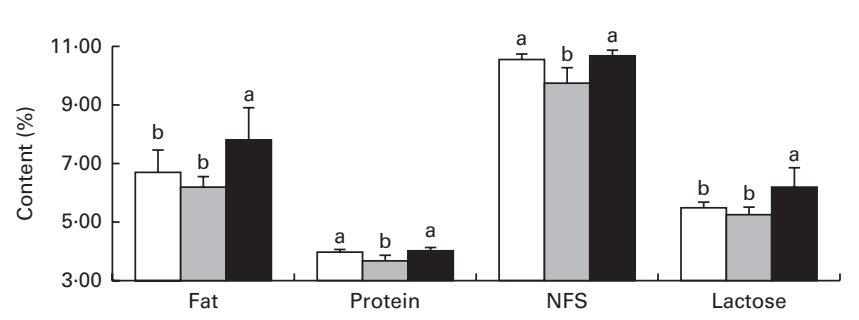

Fig. 1. Fat, protein, non-fat solid (NFS) and lactose contents in the milk of sows fed the control $(\square)$, DL-methionine $(\square)$ and DL-2-hydroxy-4-methylthiobutanoic acid $(\square)$ diets at day 14 post-partum. Values are means $(n 6)$, with standard deviations represented by vertical bars. ${ }^{a, b}$ Mean values with unlike letters were significantly different $(P<0.05)$.

Projection to latent structure with discriminant analysis of the plasma spectra from the CON, DLM and HMTBA groups was performed, and the score plots (Fig. 3(B)-(D)) clearly showed two clusters corresponding to the two groups of different dietary regimens, respectively. To further identify the important plasma metabolic changes induced by the different dietary regimens, the metabolic profiles of sows from different dietary treatment groups were compared using the OPLS-DA strategy. The corresponding coefficient loading plots showed that the plasma levels of allantoin, citrate, creatinine, formate, glycerol, lactate, methionine, myo-inositol, $\mathrm{N}$-acetyl glycoprotein and valine were higher $(P<0.05)$, whereas those of acetate, lysine, tyrosine and glucose were lower $(P<0.05)$ in the DLM group than in the CON group (Fig. 4(A) and Table 4). The corresponding coefficient loading plots also showed that the plasma levels of acetate, dimethylamine (DMA), methionine and valine were higher $(P<0.05)$ in the HMTBA group than in the CON group (Fig. 4(B) and Table 4). Multivariate data analysis showed that the plasma levels of acetate, leucine, isoleucine, lysine, tyrosine, valine and glucose were higher $(P<0.05)$, but those of alanine, glutamate, glutamine, lactate and $\mathrm{N}$-acetyl glycoprotein were lower $(P<0.05)$ in the HMTBA group than in the DLM group (Fig. 4(C) and Table 4).

\section{Discussion}

The main objective of the present study was to determine the metabolic mechanisms of milk synthesis in response to increased consumption of methionine as DLM or its hydroxy analogue HMTBA. As reported previously in the literature, conducting experimental trials using the sow as a model represents several challenges. First, given that lactation performance of sows was, to a great extent, affected by feed intake $^{(28)}$, which negatively correlates with body fatness at parturition $^{(29)}$, backfat thickness at day 0 post-partum was the first consideration in the grouping of sows in the present study. Second, previous work has shown that sows have limited ability to support mammary growth and milk production, especially during the first lactation period when feed intake is usually inadequate ${ }^{(30)}$, which indicates the importance of uniform parity in the evaluation of performance responses to dietary treatments. To minimise the potential effect of sow status on lactation performance, only the first-parity sows with similar genetic background and body weight were used in the study. Third, evidence shows that litter size is also an important factor that influences maternal tissue protein mobilisation and nutrient requirements during lactation $^{(31)}$. Thus, all litters were standardised, as described previously $^{(32)}$, to ten pigs per sow throughout the experimental period. Based on the aforementioned control, we found no statistical difference in both total feed consumption and energy intake per metabolic body weight among diets. This may allow us to discuss the difference in lactation performance in association with dietary treatments, specifically methionine levels and sources.

A particularly important finding was that increased consumption of methionine as HMTBA not only increased methionine availability for extra-intestinal tissues, but also had no effect on lysine availability, which was decreased by DLM consumption. This may be explained by the difference in the chemical nature and absorption site of methionine sources. Lysine and methionine have been reported to share the $\mathrm{B}^{\mathrm{O},+}$ and $\mathrm{b}^{0,+}$ transport systems in the mammalian intestine ${ }^{(33)}$, and an earlier study ${ }^{(34)}$ has indicated mutual inhibition occurring among lysine, methionine, cystine, ornithine and arginine when transported across the intestinal epithelium. Moreover, a down-regulation effect of L-methionine on these transporters has been reported in broiler chickens, and decreased lysine uptake has been found to be concomitant with reduced methionine transport ${ }^{(35)}$. In contrast, HMTBA is an organic acid until it is converted to L-methionine, which provides a biochemical basis for the absorption of HMTBA in the upper gastrointestinal tract ${ }^{(36)}$. Consistent with this notion, previous studies in broilers ${ }^{(37)}$ have indicated that HMTBA absorption occurs primarily in the proximal gastrointestinal tract before the small intestine. The transporter mediating HMTBA transport across the apical membrane of cell monolayers is monocarboxylate transporter $1^{(38)}$. Recent studies in pigs ${ }^{(39)}$ have further revealed that absorption of HMTBA is complete by the end of the duodenum. Moreover, diffusion into cells represents a major route of organic acid uptake and occurs most rapidly at low $\mathrm{pH}$ when more of the acid will be protonated and lipophilic ${ }^{(40)}$, which provides further support for the highly efficient absorption of HMTBA in the upper gastrointestinal tract. Taken together, the highly efficient absorption of HMTBA as an organic acid has two

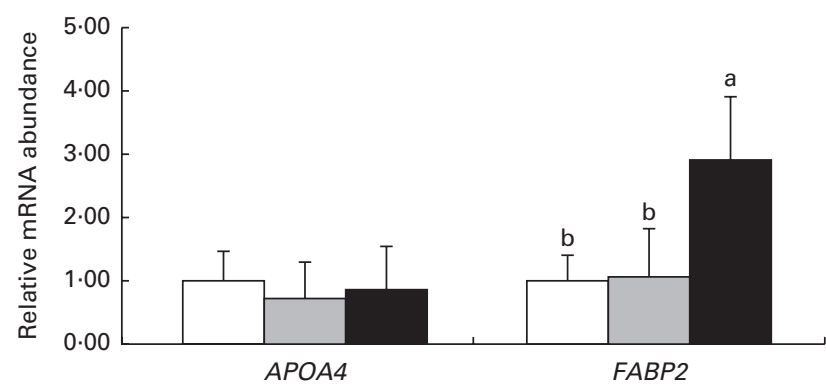

Fig. 2. mRNA abundance of genes related to nutrient transport in the jejunum of 14-d-old suckling piglets reared by sows fed the control ( $\square$ ), DL-methionine ( $\square$ ) and DL-2-hydroxy-4-methylthiobutanoic acid ( $\square$ ) diets. Values are means ( $n$ 6), with standard deviations represented by vertical bars. ${ }^{\text {a,b }}$ Mean values with unlike letters were significantly different $(P<0.05)$. $A P O A 4$, apoA-IV; FABP2, fatty acid-binding protein 2. 

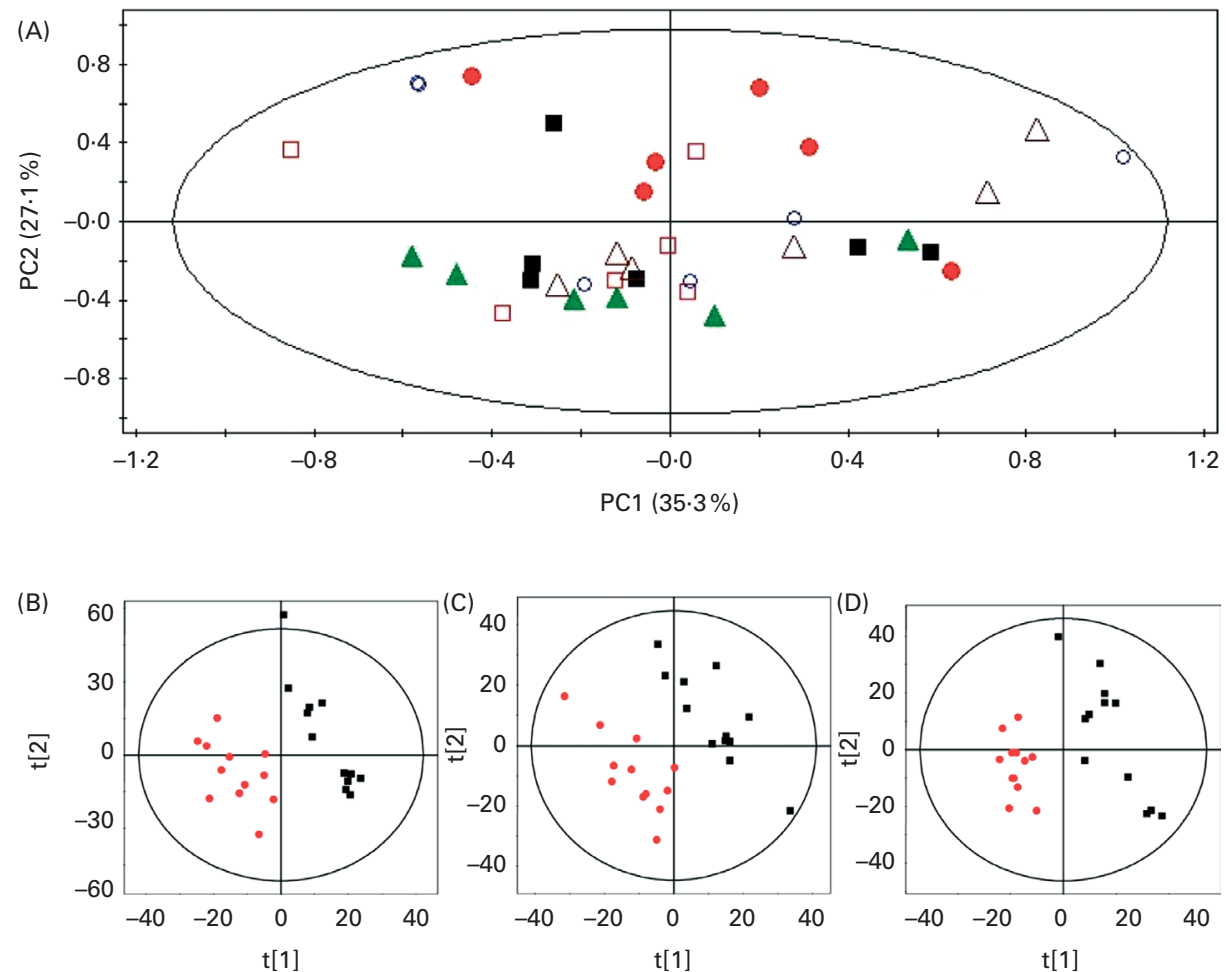

Fig. 3. (A) Principal component analysis (PC1 and PC2) and (B-D) projection to latent structure discriminant analysis score plots based on ${ }^{1} \mathrm{H}$ NMR spectra of plasma obtained from different dietary treatment groups. CON, control; DLM, DL-methionine; HMTBA, DL-2-hydroxy-4-methylthiobutanoic acid; t[1], Principal component 1 of principal component analysis score plot; t[2], principal component 2 of principal component analysis score plot. (A) $\mathbf{\square}$, CON-day 7 (d7); $\square$, CON-day 14 (d14); e, DLM-d7; O, DLM-d14; $\Lambda$, HMTBA-d7; $\triangle$, HMTBA-d14. $R^{2} X=62.4 \%, Q^{2}=0.538$. (B) , CON;, DLM. $R^{2} X=40.5 \%, R^{2} Y=0.993, Q^{2}=0.529$. (C) ¿, CON; HMTBA. $R^{2} X=38.6 \%, R^{2} Y=0.992, Q^{2}=0.741$. (D) घ, DLM; HMTBA. $R^{2} X=32.1 \%, R^{2} Y=0.998, Q^{2}=0.452$

effects, namely increasing methionine availability for extraintestinal tissues without compromising lysine availability.

Lysine is often considered to be the first-limiting AA for lactating sows sustaining milk synthesis ${ }^{(9)}$. Further studies have shown that milk protein synthesis is affected by plasma AA availability $^{(10,41,42)}$. With these in mind, the lower plasma lysine level may explain the lower milk protein synthesis in the DLM-fed sows than in the CON-fed and HMTBA-fed sows. The increased levels of the tricarboxylic acid cycle intermediate, citrate, in the DLM-fed sows might be associated with the mobilisation of body fat and muscle tissues. In support of this view, there was extensive muscle degradation in the DLMfed sows as evidenced by elevated plasma alanine and urea $\mathrm{N}$ levels ${ }^{(18)}$. In addition, the HMTBA-fed sows had relatively lower plasma glutamate and glutamine levels than the DLMfed sows, which is in agreement with our previous studies in piglets ${ }^{(16)}$. Glutamate and glutamine are major fuels for the gut ${ }^{(43)}$. Increased glutamate and glutamine catabolism following HMTBA consumption may spare essential AA as an energy source for the intestine and thus improve their extra-intestinal availability as evaluated by the net portal balance ${ }^{(16,18)}$. In the present study, there were also higher leucine, isoleucine and valine levels in the plasma of the HMTBA-fed sows than those of the DLM-fed sows, which may be a result of their enhanced net portal balance as observed in our previous studies ${ }^{(16)}$. Given that leucine and isoleucine play a central role in the activation of mammalian target of rapamycin signalling, which is a control point of protein synthesis, higher leucine and isoleucine levels in plasma may provide further explanation for the higher protein level in the milk of the HMTBA-fed sows than that of the DLMfed sows.

A second important finding was that the acetate level was increased by HMTBA consumption, but decreased by DLM consumption. Our previous studies have found that there is more than 3-fold acetate production in the distal small intestine of the HMTBA-fed pigs than that in the DLM-fed pigs ${ }^{(16)}$, which may provide an explanation for the higher plasma acetate concentration observed in the HMTBA-fed sows. There is evidence that the lactating sow can utilise acetate as a carbon source for fatty acid synthesis ${ }^{(44)}$. The increased availability of acetate may increase milk fat synthesis through the contribution of the carbon source. In support of this view, the HMTBA-fed sows showed higher fat concentration in milk than the CON- and DLM-fed sows. In addition, physiological concentrations of SCFA, particularly acetate, have been shown to exert a promoting effect on blood flow ${ }^{(45)}$, which may facilitate the transportation of nutrients from the lumen into the portal blood and from the blood into the tissues as shown in previous studies ${ }^{(16,46)}$. It appears that the potential increase in the blood flow of the HMTBAfed sows may also contribute to increased milk synthesis. 

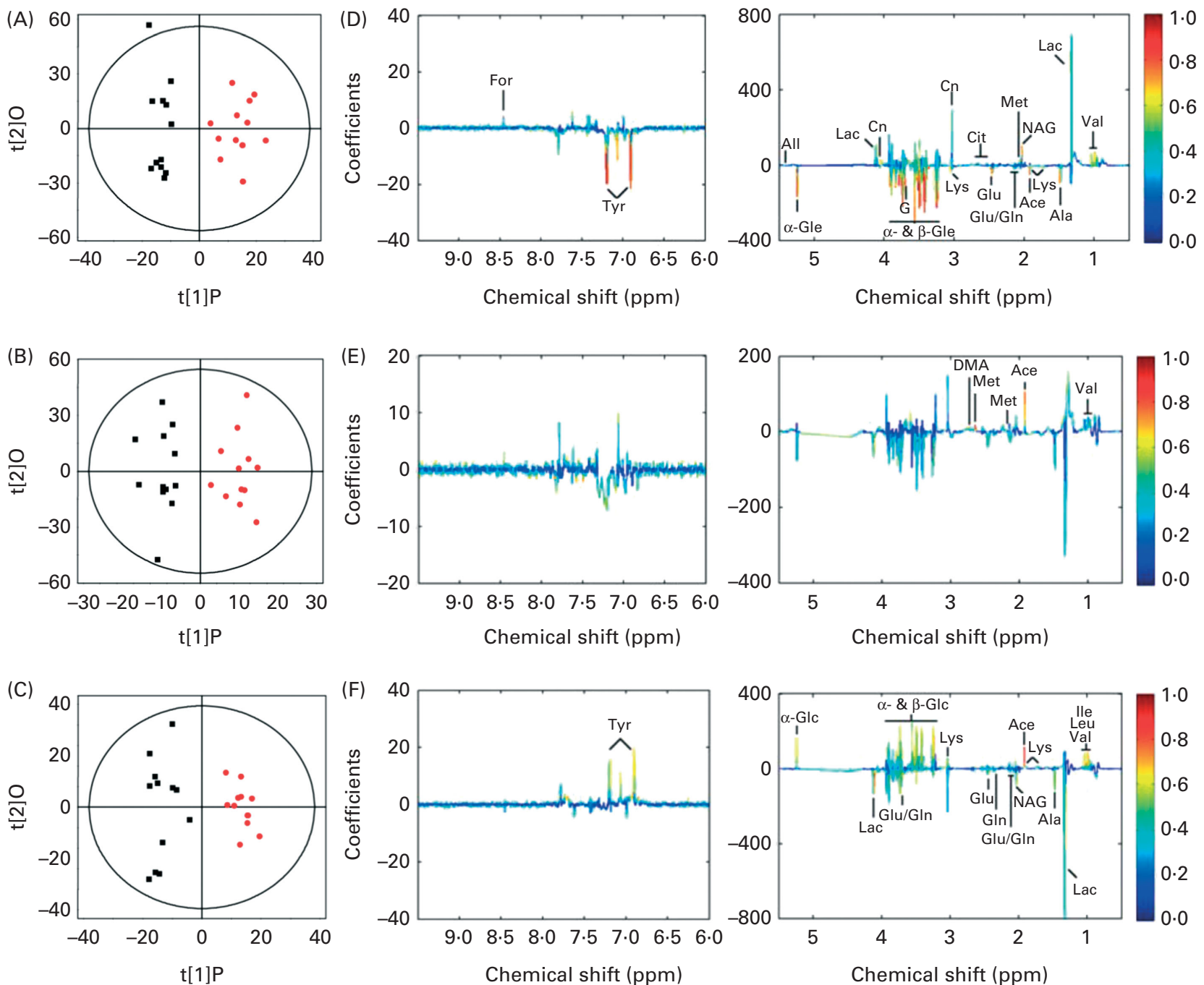

Fig. 4. Orthogonal projection to latent structure discriminant analysis score plots $(\mathrm{A}-\mathrm{C})$ derived from ${ }^{1} \mathrm{H}$ NMR spectra of plasma and corresponding coefficient loading plots (D-F) obtained from different dietary treatment groups. The colour map shows the significance of metabolite variations between the two classes of peaks. Peaks in the positive direction indicate metabolites that are more abundant in the groups in the positive direction of the first principal component. Consequently, metabolites that are more abundant in the groups in the negative direction of the first principal component are presented as peaks in the negative direction. Ace, acetate; Ala, alanine; All, allantoin; Cit, citrate; Cn, creatinine; DMA, dimethylamine; For, formate; G, glycerol; Glc, glucose; Gln, glutamine; Glu, glutamate; Ile, isoleucine; Lac, lactate; Leu, leucine; Lys, lysine; m-I, myo-inositol; Met, methionine; NAG, N-acetyl glycoprotein; Tyr, tyrosine; Val, valine. CON, control; DLM, DL-methionine; HMTBA, DL-2-hydroxy-4-methylthiobutanoic acid; ppm, parts per million; t[1]P, principal component 1 of orthogonal projection to latent structure discriminant analysis score plot; $\mathrm{t}[2] \mathrm{O}$, principal component 2 of orthogonal projection to latent structure discriminant analysis score plot.

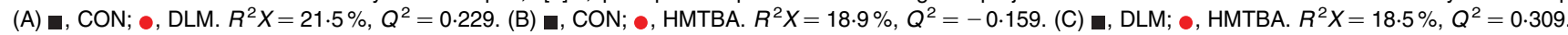

Increased piglet body weight and milk lactose level, which positively correlates with milk yield ${ }^{(47)}$ provided evidence for increased milk synthesis in the HMTBA-fed sows.

The availability of glucose is considered to be essential for overall milk synthesis and is particularly important for milk fat synthesis. Besides providing the carbon source, glucose is also used for generating reducing equivalents and producing glycerol molecules required for fatty acid synthesis ${ }^{(48)}$. The decreased glucose level in plasma provided further explanation for the lower fat level in the milk of the DLM-fed sows. Beyond the increased milk fat content, enhanced milk concentrations of free SAA including cysteine and taurine were observed in the HMTBA-fed sows. Taurine and cystine have been reported ${ }^{(49)}$ to be the most abundant milk free AA and the least abundant milk protein-bound AA, respectively.
In this regard, increased SAA supply may provide further explanation for the improved growth of neonatal pigs reared by the HMTBA diet-fed sows. In addition, consistent with previous studies $^{(50)}$, we observed the intestinal mRNA expression of $A P O A 4$ and $F A B P 2$, which are thought to participate in the uptake, intracellular metabolism and/or transport of longchain fatty acids ${ }^{(50,51)}$. Piglets reared by the HMTBA-fed sows had up-regulated FABP2 expression, which might be due to these piglets receiving more milk fat for transport and metabolism by the intestine.

A third important finding was that plasma homocysteine and creatinine levels were increased following DLM consumption, but an increased level of DMA, the hydrolysis product of asymmetric dimethylarginine (ADMA), was observed in the HMTBA-fed sows rather than in the DLM-fed sows. 
Table 4. Orthogonal projection to latent structure discriminant analysis coefficients derived from the NMR data of metabolites in plasma obtained from the different dietary treatment groups $^{*}$

\begin{tabular}{lccc}
\hline & \multicolumn{3}{c}{ Correlation coefficient $(r) \dagger$} \\
\cline { 2 - 4 } Metabolites & DLM $v$. CON & HMTBA $v$. CON & HMTBA v. DLM \\
\hline Acetate & -0.623 & 0.595 & 0.814 \\
Ala & - & - & -0.619 \\
Allantoin & 0.596 & - & - \\
Citrate & 0.726 & - & - \\
Creatinine & 0.565 & - & - \\
Dimethylamine & - & 0.577 & - \\
Formate & 0.577 & - & - \\
Glu & - & - & -0.628 \\
Gln & - & - & -0.628 \\
Glycerol & 0.643 & - & - \\
Ile & - & - & 0.622 \\
Lactate & 0.636 & - & -0.695 \\
Leu & - & - & 0.556 \\
Lys & -0.643 & 0.690 & 0.556 \\
Met & 0.692 & - & - \\
myo-Inositol & 0.561 & - & - \\
$N$-Acetyl glycoprotein & 0.666 & - & -0.553 \\
Tyr & -0.697 & - & 0.636 \\
Val & 0.712 & - & 0.584 \\
$\alpha$-Glucose & -0.694 & 0.707 & 0.699 \\
$\beta$-Glucose & -0.707 & \\
\hline
\end{tabular}

DLM, DL-methionine; CON, control; HMTBA, DL-2-hydroxy-4-methylthiobutanoic acid.

${ }^{*}$ Assignments of plasma metabolites in pigs are shown in Table 5.

$\dagger$ In the Correlation coefficient column, positive and negative signs indicate positive and negative correlations in concentrations, respectively. The correlation coefficient of $|r|>0.553$ was used as the cut-off value for statistical significance based on the significance of discrimination at the level of $P=0.05$ and df $=11$.

'-' represents the correlation coefficient of $|\eta|<0.553$.

This higher DMA concentration suggested that more amount of ADMA was degraded in the HMTBA-fed sows. Given that ADMA is an endogenous inhibitor of NO synthesis, the presumed lower level of ADMA in the HMTBA-fed sows might lead to increased NO synthesis, which, in turn, affected the blood flow and thus promoted milk synthesis, as discussed previously. Moreover, ADMA has been shown to have a strong association with cardiovascular incident risk and mortality risk ${ }^{(52-54)}$. The hydrolysis of ADMA to DMA is, therefore, considered to be a detoxification pathway. It has been reported that $90 \%$ of ADMA is metabolised by dimethylarginine dimethylaminohydrolase (DDAH), the enzyme responsible

Table 5. Assignments of plasma metabolites in pigs*

\begin{tabular}{|c|c|c|c|}
\hline No. & Metabolites & Moieties & $\delta^{1} \mathrm{H}$ (parts per million) and multiplicity \\
\hline 1 & Acetate & $\mathrm{CH}_{3}$ & $1 \cdot 92(s)$ \\
\hline 2 & Ala & $\alpha \mathrm{CH}, \mathrm{\beta CH}_{3}$ & $3 \cdot 77(q), 1 \cdot 48(d)$ \\
\hline 3 & Allantoin & $\mathrm{CH}$ & $5 \cdot 39(s)$ \\
\hline 4 & Citrate & $\mathrm{CH}_{2}$ & $2 \cdot 53(d), 2 \cdot 68(d)$ \\
\hline 5 & Creatinine & $\mathrm{CH}_{3}, \mathrm{CH}_{2}$ & $3.05(s), 4 \cdot 06(s)$ \\
\hline 6 & Dimethylamine & $\mathrm{CH}_{3}$ & $2 \cdot 73(\mathrm{~s})$ \\
\hline 7 & Formate & $\mathrm{CH}$ & $8 \cdot 46(\mathrm{~s})$ \\
\hline 8 & Glu & $\alpha \mathrm{CH}, \beta \mathrm{CH}_{2}, \gamma \mathrm{CH}_{2}$ & $3 \cdot 75(\mathrm{~m}), 2 \cdot 12(\mathrm{~m}), 2 \cdot 35(\mathrm{~m})$ \\
\hline 9 & Gln & $\alpha \mathrm{CH}, \beta_{2}, \gamma \mathrm{CH}_{2}$ & $3 \cdot 78(\mathrm{~m}), 2 \cdot 14(\mathrm{~m}), 2 \cdot 45(\mathrm{~m})$ \\
\hline 10 & Glycerol & $\mathrm{CH}_{2}, \mathrm{CH}$ & $3 \cdot 56(d d), 3 \cdot 66(d d), 3 \cdot 77(m)$ \\
\hline 11 & lle & $\alpha \mathrm{CH}, \beta \mathrm{CH}, \beta \mathrm{CH}_{3}, \gamma \mathrm{CH}_{2}, \delta \mathrm{CH}_{3}$ & $3.68(\mathrm{~d}), 1.99(\mathrm{~m}), 1.02(\mathrm{~d}), 1.26(\mathrm{~m}), 1.47(\mathrm{~m}), 0.94(\mathrm{t})$ \\
\hline 12 & Leu & $\alpha \mathrm{CH}, \beta \mathrm{CH}_{2}, \gamma \mathrm{CH}, \delta \mathrm{CH}_{3}$ & $3.73(\mathrm{t}), 1.72(\mathrm{~m}), 1.72(\mathrm{~m}), 0.96(\mathrm{~d}), 0.97(\mathrm{~d})$ \\
\hline 13 & $N$-Acetyl glycoprotein & $\mathrm{CH}_{3}$ & $2.02(\mathrm{~s}), 2.05(\mathrm{~s})$ \\
\hline 14 & Lactate & $\alpha \mathrm{CH}, \beta \mathrm{CH}$ & $4 \cdot 11(q), 1 \cdot 33(d)$ \\
\hline 15 & Lys & $\alpha \mathrm{CH}, \beta \mathrm{CH}_{2}, \gamma \mathrm{CH}_{2}, \varepsilon \mathrm{CH}_{2}$ & $3.76(\mathrm{t}), 1.91(\mathrm{~m}), 1.48(\mathrm{~m}), 1.72(\mathrm{~m}), 3.01(\mathrm{t})$ \\
\hline 16 & Met & $\alpha \mathrm{CH}, \beta_{2} \mathrm{CH}_{2}, \gamma \mathrm{CH}_{2}, \mathrm{~S}-\mathrm{CH}_{3}$ & $3 \cdot 87(\mathrm{t}), 2 \cdot 16(\mathrm{~m}), 2 \cdot 65(\mathrm{t}), 2 \cdot 14(\mathrm{~s})$ \\
\hline 17 & myo-Inositol & $1,3-\mathrm{CH}, 2-\mathrm{CH}, 5-\mathrm{CH}, 4,6-\mathrm{CH}$ & $3.60(\mathrm{dd}), 4.06(\mathrm{t}), 3 \cdot 30(\mathrm{t}), 3 \cdot 63(\mathrm{t})$ \\
\hline 18 & Val & $\alpha \mathrm{CH}, \beta \mathrm{CH}, \gamma \mathrm{CH}_{3}$ & $3.62(\mathrm{~d}), 2.28(\mathrm{~m}), 0.99(\mathrm{~d}), 1.04(\mathrm{~d})$ \\
\hline 19 & Tyr & $2,6-\mathrm{CH}, 3,5-\mathrm{CH}$ & $7 \cdot 20(\mathrm{dd}), 6 \cdot 91(\mathrm{~d})$ \\
\hline 20 & $\alpha$-Glucose & $1-\mathrm{CH}, 2-\mathrm{CH}, 3-\mathrm{CH}, 4-\mathrm{CH}, 5-\mathrm{CH}, 6-\mathrm{CH}$ & $5 \cdot 24(\mathrm{~d}), 3 \cdot 54(\mathrm{dd}), 3 \cdot 71(\mathrm{dd}), 3 \cdot 42(\mathrm{dd}), 3 \cdot 84(\mathrm{~m}), 3 \cdot 78(\mathrm{~m})$ \\
\hline 21 & $\beta$-Glucose & $1-\mathrm{CH}, 2-\mathrm{CH}, 3-\mathrm{CH}, 4-\mathrm{CH}, 5-\mathrm{CH}, 6-\mathrm{CH}$ & $4.65(d), 3.25(d d), 3.49(t), 3.41(d d), 3.46(\mathrm{~m}), 3 \cdot 73(d d), 3.90(d d)$ \\
\hline
\end{tabular}

${ }^{*}$ Chemical shift was referenced to the methyl group of lactate at $\delta 1.33$

$\dagger$ Multiplicity: s, singlet; d, doublet; t, triplet; q, quartet; m, multiplet; dd, double of doubles. 
for the breakdown of ADMA ${ }^{(55)}$. A dose-dependent reduction in DDAH activity by homocysteine has been observed in previous studies ${ }^{(56)}$. Therefore, it has been inferred that the higher homocysteine level increased the inhibition of DDAH activity and thus decreased the hydrolysis of ADMA to DMA, which may explain that the DMA level was higher in the HMTBA-fed sows than in the CON-fed sows, but was not different between the DLM-fed and CON-fed sows. In support of this view, studies in humans have shown that acute elevation of homocysteine level by oral methionine loading stimulates the formation of ADMA. Moreover, growing evidence indicates that the ADMA level is positively correlated with homocysteine and creatinine levels ${ }^{(55)}$. It would appear that higher homocysteine and creatinine levels are indicative of increased production of ADMA following DLM consumption. Given that enhanced plasma levels of homocysteine as well as ADMA ${ }^{(52-54)}$ are strongly associated with CVD in adults ${ }^{(57)}$ and with an increased risk of stroke in infants $^{(58)}$ and children ${ }^{(59)}$, HMTBA may have particular health implications for animals and humans, which warrants further studies.

In summary, increased maternal consumption of methionine as HMTBA contributed to neonatal growth and milk synthesis, which was metabolically associated with elevated methionine, valine and acetate availability for delivery to the mammary glands, neither compromising lysine and glucose availability nor increasing homocysteine accumulation. These observations offered novel insights into the mechanisms of SAA metabolism and milk synthesis regulated by methionine sources, which may have important nutrition and health implications for animals and humans.

\section{Acknowledgements}

The authors acknowledge the financial support from the Rhodimet Research Grant from Adisseo France SAS, Briand, Antony Cedex, France, the National Natural Science Foundation of China (30901042), and Sichuan Province Science Foundation for Fostering Youths Talents (2011JQ0015). The authors thank BIOTREE for technical assistance in the data analysis.

The authors' contributions are as follows: Z. F., D. W. and D. C. designed the study; H. L., H. W., X. Z., C. W., X. W., L. C., Y. L., S. X. and G. T. performed the study; X. Z., Z. F., G. L., Y. M. and H. L. analysed the data and wrote the paper.

The authors declare that there is a potential conflict of interest, given that Y. M. is an employee of Adisseo (one of the financial supporters of the present study).

\section{References}

1. Fang Z, Yao K, Zhang X, et al. (2010) Nutrition and health relevant regulation of intestinal sulfur amino acid metabolism. Amino acids 39, 633-640.

2. Shoveller AK, Stoll B, Ball RO, et al. (2005) Nutritional and functional importance of intestinal sulfur amino acid metabolism. J Nutr 135, 1609-1612.
3. Bauchart-Thevret C, Stoll B, Chang X, et al. (2008) Sulfur amino acids are necessary for normal intestinal mucosal growth in neonatal piglets. FASEB J 22, 896.1.

4. Bauchart-Thevret C, Stoll B, Chacko S, et al. (2009) Sulfur amino acid deficiency upregulates intestinal methionine cycle activity and suppresses epithelial growth in neonatal pigs. Am J Physiol Endocrinol Metab 296, E1239-E1250.

5. Daza A, Riopérez J \& Centeno C (2004) Short Communication. Changes in the composition of sows' milk between days 5 to 26 of lactation. Span J Agric Res 2, 333-336.

6. Stoll B, Henry J, Reeds PJ, et al. (1998) Catabolism dominates the first-pass intestinal metabolism of dietary essential amino acids in milk protein-fed piglets. J Nutr 128, 606-614.

7. Dai ZL, Li XL, Xi PB, et al. (2012) Metabolism of select amino acids in bacteria from the pig small intestine. Amino Acids 42, 1597-1608.

8. Schei I, Danfær A, Boman I, et al. (2007) Post-ruminal or intravenous infusions of carbohydrates or amino acids to dairy cows 1. Early lactation. Animal 1, 501-514.

9. Soltwedel KT, Easter RA \& Pettigrew JW (2006) Evaluation of the order of limitation of lysine, threonine, and valine, as determined by plasma urea nitrogen, in corn-soybean meal diets of lactating sows with high body weight loss. J Anim Sci 84, 1734-1741.

10. Guan X, Bequette BJ, Ku PK, et al. (2004) The amino acid need for milk synthesis is defined by the maximal uptake of plasma amino acids by porcine mammary glands. $J$ Nutr 134, 2182-2190.

11. Bojčuková J \& Krátký F (2006) Influence of various lysine and threonine levels in feed mixtures for lactating sows on milk quality and piglet growth. Czech J Anim Sci 51, 24-30.

12. Appuhamy J, Knapp J, Becvar O, et al. (2011) Effects of jugular-infused lysine, methionine, and branched-chain amino acids on milk protein synthesis in high-producing dairy cows. J Dairy Sci 94, 1952-1960.

13. Appuhamy JA, Knoebel NA, Nayananjalie WA, et al. (2012) Isoleucine and leucine independently regulate mTOR signaling and protein synthesis in MAC-T cells and bovine mammary tissue slices. J Nutr 142, 484-491.

14. Benevenga N \& Steele R (1984) Adverse effects of excessive consumption of amino acids. Annu Rev Nutr 4, 157-181.

15. Xie M, Hou S, Huang W, et al. (2007) Effect of excess methionine and methionine hydroxy analogue on growth performance and plasma homocysteine of growing Pekin ducks. Poult Sci 86, 1995-1999.

16. Fang Z, Luo J, Qi Z, et al. (2009) Effects of 2-hydroxy-4methylthiobutyrate on portal plasma flow and net portal appearance of amino acids in piglets. Amino acids 36, 501-509.

17. Fang Z, Luo H, Wei H, et al. (2010) Methionine metabolism in piglets fed DL-methionine or its hydroxy analogue was affected by distribution of enzymes oxidizing these sources to keto-methionine. J Agric Food Chem 58, 2008-2014.

18. Fang Z, Huang F, Luo J, et al. (2010) Effects of DL-2-hydroxy4-methylthiobutyrate on the first-pass intestinal metabolism of dietary methionine and its extra-intestinal availability. Br J Nutr 103, 643-651.

19. Swindle MM, Makin A, Herron AJ, et al. (2012) Swine as models in biomedical research and toxicology testing. Vet Pathol 49, 344-356.

20. National Research Council (1998) Requirements of Swine, 10th ed. Washington, DC: National Academic Press.

21. Dourmad J-Y, Étienne M, Valancogne A, et al. (2008) InraPorc: a model and decision support tool for the nutrition of sows. Anim Feed Sci Technol 143, 372-386. 
22. Wang YB, Liu DH, Zhou XH, et al. (2003) Effect of applying ultrasonic milk analyzer for detecting composition of cow milk adulterated with table salt and sugar. $J$ Zhejiang University (Agric Life Sci) 29, 671-674.

23. Roberts RF \& Roberts WL (2004) Performance characteristics of a recombinant enzymatic cycling assay for quantification of total homocysteine in serum or plasma. Clin Chim Acta 344, 95-99.

24. Livak KJ \& Schmittgen TD (2001) Analysis of relative gene expression data using real-time quantitative PCR and the $2^{-\Delta \Delta C_{\mathrm{t}}}$ method. Methods 25, 402-408.

25. Trygg J \& Wold S (2002) Orthogonal projections to latent structures (O-PLS). J Chemom 16, 119-128.

26. Cloarec O, Dumas ME, Trygg J, et al. (2005) Evaluation of the orthogonal projection on latent structure model limitations caused by chemical shift variability and improved visualization of biomarker changes in $1 \mathrm{H}$ NMR spectroscopic metabonomic studies. Anal Chem 77, 517-526.

27. Lindgren F, Hansen B, Karcher W, et al. (1996) Model validation by permutation tests: applications to variable selection. J Chemom 10, 521-532.

28. Kruse S, Traulsen I \& Krieter J (2011) Analysis of water, feed intake and performance of lactating sows. Livest Sci 135, $177-183$.

29. Eissen J, Kanis E \& Kemp B (2000) Sow factors affecting voluntary feed intake during lactation. Livest Prod Sci 64, $147-165$.

30. Kim S, Hurley W, Wu G, et al. (2009) Ideal amino acid balance for sows during gestation and lactation. J Anim Sci 87, E123-E132.

31. Kim S \& Easter R (2001) Nutrient mobilization from body tissues as influenced by litter size in lactating sows. J Anim Sci 79, 2179-2186.

32. Kusina J, Pettigrew J, Sower A, et al. (1999) Effect of protein intake during gestation and lactation on the lactational performance of primiparous sows. J Anim Sci 77, 931-941.

33. Bröer S (2008) Amino acid transport across mammalian intestinal and renal epithelia. Physiol Rev 88, 249-286.

34. Hagihira H, Lin E, Samiy A, et al. (1961) Active transport of lysine, ornithine, arginine and cystine by the intestine. Biochem Biophys Res Commun 4, 478-481.

35. Soriano-García JF, Torras-Llort M, Moretó M, et al. (1999) Regulation of L-methionine and L-lysine uptake in chicken jejunal brush-border membrane by dietary methionine. Am J Physiol Regul Integr Comp Physiol 277, R1654-R1661.

36. Dibner J \& Buttin P (2002) Use of organic acids as a model to study the impact of gut microflora on nutrition and metabolism. J Appl Poult Res 11, 453-463.

37. Richards J, Atwell C, Vazquez-Anon M, et al. (2005) Comparative in vitro and in vivo absorption of 2-hydroxy-4 (methylthio) butanoic acid and methionine in the broiler chicken. Poult Sci 84, 1397-1405.

38. Martín-Venegas R, Rodríguez-Lagunas M, Geraert $\mathrm{P}$, et al. (2007) Monocarboxylate transporter 1 mediates DL-2hydroxy-(4-methylthio) butanoic acid transport across the apical membrane of Caco-2 cell monolayers. J Nutr 137, 49-54.

39. Jendza J, Geraert P, Ragland D, et al. (2011) The site of intestinal disappearance of DL-methionine and methionine hydroxy analog differs in pigs. J Anim Sci 89, 1385-1391.

40. Walter A \& Gutknecht J (1984) Monocarboxylic acid permeation through lipid bilayer membranes. J Membr Biol 77, 255-264.

41. Guan X, Bequette BJ, Calder G, et al. (2002) Amino acid availability affects amino acid flux and protein metabolism in the porcine mammary gland. J Nutr 132, 1224-1234.
42. Guan X, Pettigrew J, Ku P, et al. (2004) Dietary protein concentration affects plasma arteriovenous difference of amino acids across the porcine mammary gland. J Anim Sci $\mathbf{8 2}$, 2953-2963.

43. Janeczko MJ, Stoll B, Chang X, et al. (2007) Extensive gut metabolism limits the intestinal absorption of excessive supplemental dietary glutamate loads in infant pigs. J Nutr 137, 2384-2390.

44. Pettigrew J, Gill M, France J, et al. (1992) A mathematical integration of energy and amino acid metabolism of lactating sows. J Anim Sci 70, 3742-3761.

45. Kvietys P \& Granger D (1981) Effect of volatile fatty acids on blood flow and oxygen uptake by the dog colon. Gastroenterology 80, 962-969.

46. Guan X, Stoll B, Lu X, et al. (2003) GLP-2-mediated up-regulation of intestinal blood flow and glucose uptake is nitric oxide-dependent in TPN-fed piglets. Gastroenterology 125, $136-147$.

47. Shahbazkia HR, Aminlari M, Tavasoli A, et al. (2010) Associations among milk production traits and glycosylated haemoglobin in dairy cattle; importance of lactose synthesis potential. Vet Res Commun 34, 1-9.

48. Luick JR \& Kleiber M (1961) Quantitative importance of plasma glucose for synthesis of milk fat glycerol. Am J Physiol 200, 1327-1329.

49. Wu G \& Knabe DA (1994) Free and protein-bound amino acids in sow's colostrum and milk. J Nutr 124, 415-424.

50. Wang J, Chen L, Li P, et al. (2008) Gene expression is altered in piglet small intestine by weaning and dietary glutamine supplementation. J Nutr 138, 1025-1032.

51. Lu S, Yao Y, Meng S, et al. (2002) Overexpression of apolipoprotein A-IV enhances lipid transport in newborn swine intestinal epithelial cells. J Biol Chem 277, 31929-31937.

52. Shi B, Ni Z, Zhou W, et al. (2010) Circulating levels of asymmetric dimethylarginine are an independent risk factor for left ventricular hypertrophy and predict cardiovascular events in pre-dialysis patients with chronic kidney disease. Eur J Intern Med 21, 444-448.

53. Abedini S, Meinitzer A, Holme I, et al. (2009) Asymmetrical dimethylarginine is associated with renal and cardiovascular outcomes and all-cause mortality in renal transplant recipients. Kidney Int 77, 44-50.

54. Young JM, Terrin N, Wang X, et al. (2009) Asymmetric dimethylarginine and mortality in stages 3 to 4 chronic kidney disease. Clin J Am Soc Nephrol 4, 1115-1120.

55. Atamer A, Ecder SA, Atamer Y, et al. (2012) The effects of asymmetric dimethylarginine (ADMA), nitric oxide (NO) and homocysteine (Hcy) on progression of mild chronic kidney disease (CKD): relationship between clinical and biochemical parameters In Chronic Kidney Disease, pp. 197-208 [M Gööz, editor]. Rijeka, Croatia: InTech.

56. Stühlinger MC, Tsao PS, Her J-H, et al. (2001) Homocysteine impairs the nitric oxide synthase pathway role of asymmetric dimethylarginine. Circulation 104, 2569-2575.

57. Stipanuk MH (2004) Sulfur amino acid metabolism: pathways for production and removal of homocysteine and cysteine. Annu Rev Nutr 24, 539-577.

58. Hogeveen M, Blom HJ, van Amerongen M, et al. (2002) Hyperhomocysteinemia as risk factor for ischemic and hemorrhagic stroke in newborn infants. $J$ Pediatr $\mathbf{1 4 1}$ 429-431.

59. van Beynum IM, Smeitink JAM, den Heijer M, et al. (1999) Hyperhomocysteinemia: a risk factor for ischemic stroke in children. Circulation 99, 2070-2072. 